\title{
DANIEL FAUVEL, L'affaire Ferdinand Delamare a-t-elle inspiré Flaubert?
}

\section{Ida Merello}

\section{(2) OpenEdition}

\section{Journals}

\section{Édition électronique}

URL : https://journals.openedition.org/studifrancesi/45355

DOI : 10.4000/studifrancesi.45355

ISSN : 2427-5856

\section{Éditeur}

Rosenberg \& Sellier

\section{Édition imprimée}

Date de publication : 1 août 2021

Pagination : 395

ISSN : 0039-2944

\section{Référence électronique}

Ida Merello, « DANIEL FAUvel, L'affaire Ferdinand Delamare a-t-elle inspiré Flaubert? », Studi Francesi [En ligne], 194 (LXV | II) | 2021, mis en ligne le 01 septembre 2021, consulté le 14 octobre 2022. URL : http://journals.openedition.org/studifrancesi/45355; DOI : https://doi.org/10.4000/studifrancesi. 45355

Ce document a été généré automatiquement le 14 octobre 2022.

\section{(c) (i) (9)}

Creative Commons - Attribution - Pas d'Utilisation Commerciale - Pas de Modification 4.0 International - CC BY-NC-ND 4.0

https://creativecommons.org/licenses/by-nc-nd/4.0/ 


\title{
DANIEL FAUVEL, L'affaire Ferdinand Delamare a-t-elle inspiré Flaubert?
}

\author{
Ida Merello
}

\section{RÉFÉRENCE}

DANIEL FAUVEL, L'affaire Ferdinand Delamare a-t-elle inspiré Flaubert?, Petit-Caux, Editions

Wooz, 2020, $112 \mathrm{pp}$.

1 Après la publication de Mme Bovary, la critique biographique s'est déchaînée pour retrouver les modèles des personnages de Flaubert. Les enquêtes ont commencé après sa parution, et Claudine Gothot-Mersch a bien montré dans son livre sur la Genèse de Mme Bovary la complexité des suggestions qui se sont fondues dans le creuset de l'œuvre. À la fin des années 1880, dans "Le Journal de Rouen", Georges Dubosc avait localisé dans Ry le pays de Yonville l'Abbaye, et il justifie cette conviction, comme d'ailleurs le remarque Daniel Fauvel, car «Flaubert avait connu par lui-même toute cette histoire les principaux personnages était lié à sa famille et les détails particuliers, les notes intimes, lui furent pendant un séjour à Ry même pour cette étude fournis par le pharmacien de l'endroit qu'il connaissait beaucoup» (p. 3). Dans la recherche des modèles possibles pour les personnages de Flaubert, au début du siècle, Georges Clérembray en 1912 s'était distingué par une attention aux généalogies, et Georgette Leblanc Mæterlinck, l'année suivante, par la tentative de faire état d'une solidarité féminine à l'égard d'Emma. L'œuvre de Daniel Fauvel, récemment parue, ajoute une autre «affaire Delamare» à la plus connue, montrant comment la chasse aux faits divers se poursuit jusqu'à maintenant.

2 L'A. avait déjà consacré un article à l'affaire Laquerrière, plaidé en 1848, où un mari avait été accusé d'avoir empoisonné sa femme avec l'arsenic, et l'officier de santé Delamare, appelé au secours n'avait pu que constater les conditions désespérées de la femme. 
3 Ici D. Fauvel vient de découvrir une autre affaire Delamare, où un autre Delamare, Ferdinand, médecin et pharmacien, accueille sa maîtresse dans son cabinet d'étude, à l'intérieur de sa maison, permettent ainsi à sa femme de l'accuser de concubinage. Seul le concubinage à l'époque, et non l'adultère, représentait en effet une culpabilité pour le mari. C'est une description assez cocasse celle que D. Fauvel décrit, car l'épouse du traître doit pratiquer deux trous dans le mur du cabinet de son mari pour montrer «le crime» aux témoins et aux hommes de loi, pour prouver ainsi le concubinage: ce qui lui permettrait de rentrer en possession de sa dot.

4 La suite des études montre qu'il est suffisant de regarder à travers les fissures de deux minces trous pour voir grouiller tout un monde qui partage avec Mme Bovary la même occupation. Ce qui n'a évidemment rapport avec l'art de Flaubert, mais qui peut expliquer aisément pourquoi un sujet pareil est surgi soudain à l'esprit. 